\title{
Transformational Leadership and Job Satisfaction
}

\author{
Jalal R. M. Hanaysha", Khawaja Khalid, Nik Kamariah Nik Mat, Fosa Sarassina, \\ Muhd Yahya Bin Ab Rahman, Ahmad Sazali Bin Zakaria
}

Othman Yeop Abdullah Graduate School of Business,University Utara Malaysia, Sintok, Kedah, 06010, Malaysia

\begin{abstract}
A vast literature describes transformational leadership in terms of leader having charismatic and inspiring personality, stimulating followers, and providing them with individualized consideration. A considerable empirical support exists for transformation leadership in terms of its positive effect on followers with respect to criteria like effectiveness, extra role behaviour and organizational learning. This study aims to explore the effect of transformational leadership characteristics on followers' job satisfaction. Survey method was utilized to collect the data from the respondents. The study reveals that individualized consideration and intellectual stimulation affect followers' job satisfaction. However, intellectual stimulation is positively related with job satisfaction and individualized consideration is negatively related with job satisfaction. Leader's charisma or inspiration was found to be having no affect on the job satisfaction. The three aspects of transformational leadership were tested against job satisfaction through structural equation modeling using Amos.
\end{abstract}

Keywords Transformational, Leadership Charisma, Individualized Consideration, Intellectual Stimulation, Job Satisfaction

\section{Introduction}

Organizations are social systems which assume human resources as one of the main factors for achieving competiti ve advantage and influencing organizational effectiveness[1]. Organizations require cooperation among managers and employees for achievement of their goals and objectives. Therefore, the study of employees' job satisfaction is important in organizational as well as in academic context. Job satisfaction is an important efficiency index for studying organization as satisfaction has a significant impact on employees' behaviour and work attitude indirectly. Fang, Chang and Chen[2] indicate that job satisfaction has a significant, positive and direct influence on organizational commitment and work performance. Job satisfaction resides from employees' ability to have a clear understanding of the objectives and the goals of the organization[3]. In Western cultures, job satisfaction comes from the ability of employees to have control over the jobs, or feelings of empowerment in their lives at work[4].

Transformational leadership has been of great interest to many researchers in current era and adoptingtransformation al leadership behaviour helps in the success of the organization[5]. Transformational leadership takes into account the development and strategic thinking[1], thus enables the organizational change process to happen more

* Corresponding author:

jalal_marketting@yahoo.com(Jalal R. M. Hanaysha)

Published online at http://journal.sapub.org/economics

Copyright (C) 2012 Scientific \& Academic Publishing. All Rights Reserved rapidly than other leadership styles. Krishnan[6] further explains that transformational leadership enables the creation of value system congruence between the leader and followers, thus facilitating condition where the leader and followers motivate each other to achieve the organizational goals. Doherty and Danylchuk[7] suggest that transformational leadership is of great significance because transformational leadership helps with the increase of satisfaction and commitment of staff through giving impetus and vision. However, some others cast doubt on its application. Due to the extreme importance of job satisfaction and transformational leadership, number of researches was conducted in this topic but there is a limited research available with respect to this topic in Malaysian context.

Pihie, Sadeghi and Ellias[8] conducted a research in Malaysian research universities with respect to leadership styles and job satisfaction of academic staff. However, there is limited research conducted for administrative/clerical staff working in different colleges, departments or schools in Malaysian universities. The job satisfaction of administrative /clerical staff is important for uplift of Malaysian universities as they are supposed to attract international students, attain excellence in administrative procedures and plan to achieve high international rankings. Since job satisfaction correlates positively with organizational effectiveness[9], it becomes significantly important to study the job satisfaction level of the university administrative/clerical staff related to the transformational leadership style of concerned department/ school head. 


\section{Literature Review}

\subsection{Job Satisfaction}

McShane[10] defines job satisfaction as the individual's evaluation of his/her own work in terms of the context and content of the work. Job satisfaction of employees often includes such elements as: the job itself, the relationship with the supervisor and co-workers, management beliefs, future opportunity, work environment, and compensation[11]. According to Morris[11], employee job satisfaction is an important factor affecting customer satisfaction.

Past studies have used numerous antecedents of job satisfaction other than transformational leadership. For instance, transactional leadership[12], compensation system [13], contingent reward[14], employee empowerment[3], and trust[15]. Most of these antecedents have been found to be positively related with job satisfaction.

\subsection{Transformational Leadership}

Bass and Avolio[16] define transformational leadership as the one which helps increasing employees' concern and strengthening their level of perception as well as their acceptance of the groups' vision and aims. Transformational leaders facilitate new understandings by increasing or altering awareness of issues. Resultantly, they foster inspiration and excitement in placing extra efforts to achieve common goals[12].

Bass[17] proposes that transformational leadership is comprised of charismatic behaviours such as role modeling, risk sharing and attributed charisma. In addition, transformational leadership includes intellectual stimulation consisting of encouraging creativity and change in followers. It also entails the degree to which the leader challenges assumptions, takes risks and solicits followers' ideas. Finally, individualized consideration which implies leaders paying attention to each follower's needs and wants by mentoring, supporting, encouraging and coaching followers to use their competence.

Riaz and Haider,[12] conducted a study to determine the impact of transformational and transactional leadership style on job success and career satisfaction in context of Pakistan. The results of their study showed that transformational leadership style is positively related to job success and career satisfaction. This finding is consistent with[14],[13] and[3]. They found that transformational leaders had more positive impact on job and overall satisfaction.

Furthermore, Lee, Cheng, Yeung and Lai[18] studied the relationships among transformational leadership, team performance and service quality in retail banks, and their findings indicate that among different dimensions of transformational leadership, only intellectual stimulation is significantly related to team leader job satisfaction.

Based on above literature review, the following hypotheses are formulated

$\mathrm{H}_{1}$ : There is a positive relationship between charisma and job satisfaction
$\mathrm{H}_{2}$ : There is a positive relationship between individualized consideration and job satisfaction

$\mathrm{H}_{3}$ : There is a positive relationship between intellectual stimulation and job satisfaction

\section{Methodology}

Based on the arguments about the topic, the following research framework is developed for the study.

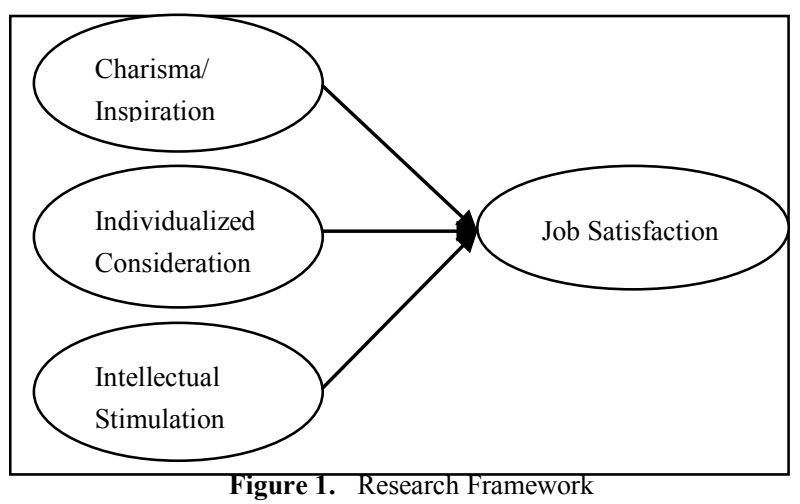

This research was conducted among administrative/ clerical staff involved in graduate and postgraduate affairs in three universities located in Kedah and Perlis. The universities are: Universiti Utara Malaysia (UUM), Universiti Technology MARA (UiTM) and College Universiti Insaniah (KUIN). A random sample of $320^{1}$ employees was selected and questionnaires were e-mailed to the respondents ${ }^{\mathrm{i}}$. A total of 100 questionnaires were returned providing response rate of $31.5 \%$. However, data cleaning resulted in 97 usable responses for the final analysis.

An 18 item scale from the MultiFactor Leadership Questionnaire was used to measure the three components of transformational leadership[17, 20, 21], where by four items were used to measure charisma/ inspiration, ten items for individualized consideration, and four items individualized consideration. In addition, a five item questionnaire was used to measure job satisfaction, with the variables including wage, promotion, job, supervisors and colleagues[22]. A five point Likert scale was used ranging from 1 (strongly disagree) to 5 (strongly agree).

Before conducting data analysis on Amos, the data was cleaned and normalized using SPSS 14.0. After that Exploratory Factor Analysis and reliability test (Cronbach's alpha) was done on SPSS. Final analysis and model was done on Amos 16 after conducting Confirmatory Factor Analysis in the first stage.

\section{Findings}

A total of 29 items were included in the questionnaire. 23 items measured transformational leadership and 6 items were used as classification questions. We had acceptable

\footnotetext{
${ }^{1}$ Sample size was calculated using Krejcie and Morgan table (1970)[19].
} 
Cronbach's $\alpha$ reliability estimates at 0.833 for Charisma/ Inspiration, 0.840 for Individualized Consideration, 0.710 for Intellectual Stimulation and 0.756 for Job Satisfaction. All results are above the 0.60 cut-off point for internal consistency of the measures[23].

The results of CFA for all the constructs provided support for goodness of fit. As far as CFA results for individual constructs were concerned then, for Charisma/ Inspiration, $\chi^{2}=0.766(\mathrm{p}=0.682), \chi^{2} / d f=2.0$, Ratio $=$ 0.383 , RMSEA $=0$, GFI $=0.996$; for Individualized Consideration, $\chi^{2}=31.061(\mathrm{p}=0.054), \chi 2 / d f=20$, Ratio $=$ 1.553 , RMSEA $=0.076$, GFI $=0.922$; for Intellectual Stimulation, $\chi^{2}=7.898(\mathrm{p}=0.019), \chi^{2} / d f=2.0$, Ratio $=$ 3.949, RMSEA $=0.175$, GFI $=0.962$; and for Job Satisfaction, $\chi 2=6.0(\mathrm{p}=0.306), \chi 2 / d f=5$, Ratio $=1.2$, RMSEA $=0.046, \mathrm{GFI}=0.976$. We also achieved fit model statistics for our overall model shown in Figure 2 where $\chi^{2}$ $=84.502(\mathrm{p}=0.464), \chi^{2} / d f=1.006, \mathrm{RMSEA}=0.008, \mathrm{GFI}$ $=0.901, \mathrm{TLI}=0.998$ and $\mathrm{CFI}=0.998$.

Descriptive statistics reveal that almost $30 \%$ of respondents are in age group of $35-40$, almost $62 \%$ are females, more than $50 \%$ are Malaysians and almost $31 \%$ have experience of 6 to 10 years and almost $31 \%$ respondents have experience of more than 15 years. Table 1 indicates the significant and direction of relationships between different constructs used in study. Intellectual stimulation is found to be significantly related to job satisfaction. However, for individual consideration, the relationship is significant but in the negative direction ( $\mathrm{p}$ value $=0.042$ ). Thus, this hypothesis is not supported. Charisma is not statistically significant with job satisfaction ( $p$ value $=0.107$ ), hence this hypothesis is not supported. Overall, finding of the study leads to the support for hypotheses 3 .

Table 1. Regression Weights

\begin{tabular}{|l|rccc|}
\hline & Estimate & S.E. & C.R. & P \\
\hline Job Satisfaction <-. Charisma & .607 & .292 & 1.610 & .107 \\
Job Satisfaction <-. Individual Consideration & -690 & .129 & -2.037 & .042 \\
Job Satisfaction <-- Intellectual Stimulation & .555 & .050 & 2.545 & .011 \\
\hline
\end{tabular}

\section{Conclusions}

Positive relationship between intellectual stimulation and job satisfaction shows that result is consistent with[1],[24], and[18]. The hypothesis 2 was not supported as individualized consideration is negatively related to job satisfaction. A possible explanation of this situation could be that employees could not meet their leaders due to leader's busy schedule leading to lack of individual consideration, thus, the lesser the individual consideration, the higher the job satisfaction. We did not get any support for this finding from past research. As limited studies have been conducted in Malaysia so far, therefore the contextual difference in the culture might be responsible for this new finding. So we suggest conducting more studies in Malaysian context in order to explore this situation. Lastly, the regression weight for charisma and job satisfaction is also positive $(0.607)$ but is not statistically significant. This finding is consistent with Lee et al[18]. Our results are also consistent with the findings of the study conducted by[25] in food and banking sector which found significant positive relationship between intellectual stimulation and job satisfaction but revealed no significant relationship between charisma and job satisfaction. Future researches can study the topic with greater detail by inclusion of certain moderating or mediating variables between transformational leadership in other sectors of Malaysia.

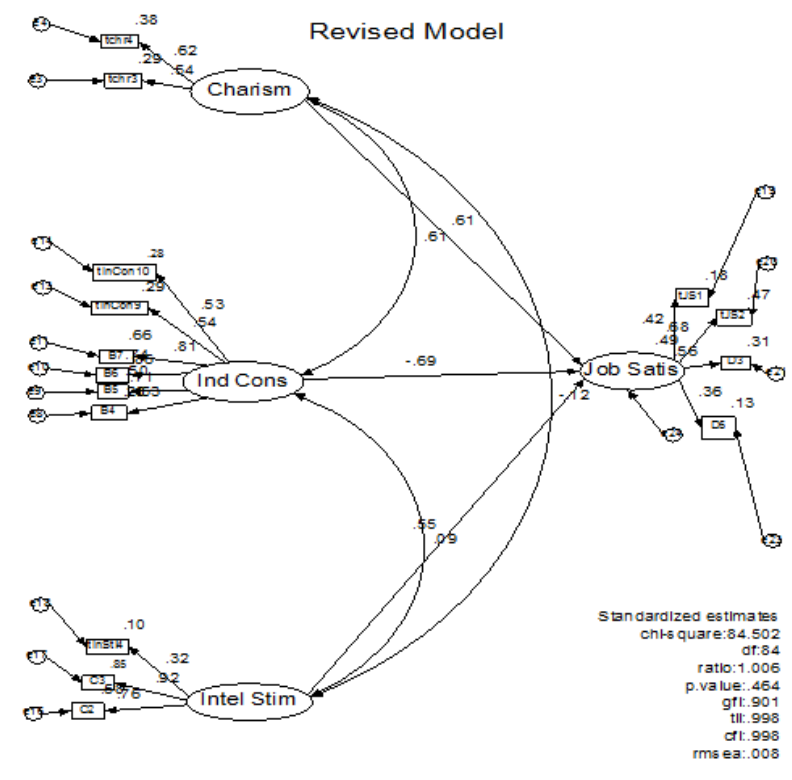

Figure 2. Revised Model

\section{ACKNOWLEDGEMENTS}

We would like to thank Prof Dr. Nik Kamariah Nik Mat and Sukma Pea for their helpful comments and assistance on an earlier version of this paper.

\section{REFERENCES}

[1] Sulieman, I. S. Mohammad, Hussein A. AL-Zeaud and Ayat M. E. Batayneh. "The relationship between transformational leadership and employees' satisfaction at Jordanian private hospitals". BEH - Business and Economic Horizons, vol.5, no.2, pp. 35-46, 2011.

[2] Chung-Hsiung Fang, Sue-Ting Chang and Guan-Li Chen . "Applying structural equation model to study of the relationship model among leadership style, satisfaction, organization commitment and performance in hospital industry". In Proceedings of International Conference on E-Business and Information System Security, Taiwan, 2009.

[3] Amarjit Gill, Alan B Flaschner, Charul Shah and Ishaan Bhutani. "The relations of transformational leadership and 
empowerment with employee job satisfaction: A study among Indian restaurant employees". Business and Economics Journal, vol.18, 2010.

[4] Innstrand, S Tone, Espnes, G Arild and Mykletun, Reidar. "Job stress, burnout and job satisfaction: an intervention study for staff working with people with intellectual disabilities". Journal of Applied Research in Intellectual Disabilities, Vol.17, no.2, pp. 119-126, 2004.

[5] Laohavichien Tipparat, Fredendall, L. D and Cantrell, R. Stephen. "The effects of transformational and transactional leadership on quality improvement", The Quality Management Journal, vol.16, no.2, pp.7-24, 2009.

[6] Venkat R. Krishnan. "Transformational leadership and outcomes: Role of relationship duration". Leadership and Organizational Journal, vol.26, no.5/6, pp.442-457, 2005.

[7] Alison J. Doherty, and Karen E. Danylchuk. "Transformational and transactional leadership in interuniversity athletics management". Journal of Sport Management, vol.10, no.3, pp. 292-309, 1996.

[8] Zaidatol A. L. Pihie, Amir Sadeghi and Habibah Ellias. "Analysis of head of departments leadership styles: Implications for improving research university management practices", in Proceedings of Procedia- Social and behavioural sciences, vol.29, pp. 1081-1090, 2011.

[9] John O. Okpara, Michael Squillace and Emmanuel A. Erondu. "Gender differences and job satisfaction: a study of university teachers in the United States", Women Management Review, vol.20, no.3, pp. 177-190, 2005.

[10] Steven L. McShane. Canadian organizational behavior (5th edition), McGraw-Hill Ryerson, Toronto, 2004.

[11] Ted Morris. "Employee satisfaction: maximizing the return on human capital". CMA - The Management Accounting Magazine, vol.69, no.10, pp. 15-18, 1995.

[12] Adnan Riaz and Mubarak H. Haider. "Role of transformational and transactional leadership on job satisfaction and career satisfaction". Business and Economic Horizons, vol.1, no.1, pp. 29-38, 2010.

[13] Iwan I. Wiratmadja, Rajesri Govindaraju and Agoes G. Rahyuda. "The influence of transformational leadership style and compensation system on the performance of university lecturer". In Proceedings of the 9th Asia Pacific Industrial Engineering \& Management Systems Conference, Indonesia, pp. $693-699,2008$.
[14] Yair Berson and Jonathan D. Linton. "An examination of the relationships between leadership style, quality, and employee satisfaction in R\&D versus administrative environments. R\&D Management, vol.35, no.1, pp.51-60, 2005.

[15] Timothy Bartram and Gian Casimir. "The relationship between leadership and follower in-role performance and satisfaction with the leader: The mediating effects of empowerment and trust in the leader". Leadership \& Organization Development Journal, vol.23, no.1, pp. 4-19, 2007.

[16] Bernard M. Bass and Bruce $J$ Avolio. Improving Organizational Effectiveness through Transformational Leadership, Sage, Thousand Oaks, CA, 1994.

[17] Bernard M. Bass. Leadership and Performance beyond Expectations, Free Press, NY, 1985.

[18] Peter K. C. Lee, T.C. Edwin Cheng, Andy C.L. Yeung and Kee-hung Lai. "An empirical study of transformational leadership, team performance and service quality in retail banks," Omega, Vol. 39, pp. 690-701, 2011.

[19] Robert V. Krejcie and Daryle W. Morgan. "Determining sample size for research Activities", Educational and Psychological Measurement, vol.30, pp. 607-610, 1970.

[20] Bernard M. Bass. "From transactional to transformational leadership: learning to share the vision", Organizational Dynamics, vol. 18, pp. 19-31, 1990.

[21] Bernard M. Bass. A New Paradigm for Leadership: An Inquiry into Transformational Leadership, US Army Research Institute, Alexandria, VA, 1996.

[22] Patricia C. Smith, Lorne M. Kendall and Charles L. Hulin. The measurement of satisfaction in work and retirement. Rand McNally, Chicago, 1969.

[23] Jum C. Nunnally. Psychometric theory (2nd ed.). McGraw-Hill, New York, 1978.

[24] Hsing-Chau Tseng, Long-Min Kang. "Does Regulatory Focus Affect Job Satisfaction of Police officers?" In Proceedings of Sixth AIMS International Conference on Management, India, pp. 1-7, 2008.

[25] Charles R. Emery and Katherine J. Barker.'The effect of transactional and transformational leadership styles on the organizational commitment and job satisfaction of customer contact personnel". Journal of Organizational Culture, Communications and Conflict, vol.11, no.1, pp.77-90, 2007. 